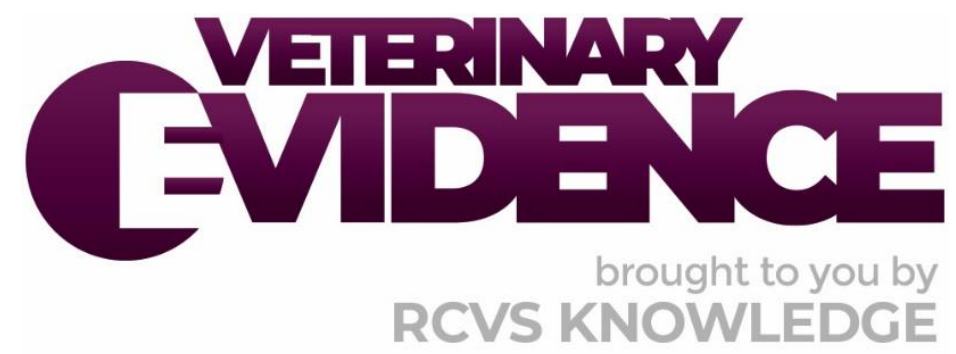

\title{
In dogs with osteoarthritis, how effective is treatment with tramadol in providing analgesia?
}

\section{A Knowledge Summary by}

Adrian Wong BVSc(Hons I) GradCertSAECC ${ }^{1^{*}}$

Fernando Martinez Taboada LV CertVA PGCert(Biostats) DipECVAA ${ }^{1}$

\footnotetext{
${ }^{1}$ University Veterinary Teaching Hospital, School of Veterinary Science, The University of Sydney, 65 Parramatta Road, Camperdown, NSW 2050, Australia

*Corresponding Author (adrianjhwong@gmail.com)
}

ISSN: 2396-9776

Published: 24 Jun 2021

in: The Veterinary Evidence journal Vol 6, Issue 2

DOI: https://doi.org/10.18849/ve.v6i2.401

Reviewed by: Adewole Adekola (PhD Student DVM MVSc MPH), Andy Morris (BSc(Hons) BVSc

CertAVP(GSAS) MRCVS) and Thomas Towers (VetMB MA CertAVP(VA) MRCVS) 


\section{PICO question}

In dogs with osteoarthritis how effective is treatment with tramadol in reducing the severity of the clinical signs associated with pain when compared to no treatment?

\section{Clinical bottom line}

\section{Category of research question}

\section{Treatment}

\section{The number and type of study designs reviewed}

Two papers were critically reviewed. There was one randomised crossover controlled trial and one nonrandomised controlled trial

\section{Strength of evidence}

\section{Strong}

\section{Outcomes reported}

Budsberg et al. (2018) found no significant differences in the objective gait analyses (vertical ground reaction forces, and peak vertical force) between baseline and end of treatment, between tramadol and placebo. Similarly, there was no significant difference in the proportion of dogs with positive response based on the subjective Canine Brief Pain Inventory questionnaire (CBPI) between tramadol and placebo. The positive control of carprofen yielded significant differences to both placebo and tramadol in all outcomes measured.

Malek et al. (2012) found no significant differences in the objective outcomes measured (gait analyses, and total daily activity) between tramadol and placebo. There were significant improvements in the subjective CBPI (total score, pain severity and pain interference score) between the baseline and end of treatment, within the tramadol group. However, there was no significant difference in the percentage change of the total score, pain severity or pain interference score between all treatment groups including tramadol and placebo

\section{Conclusion}

In dogs with osteoarthritis, the use of tramadol alone did not demonstrate any significant analgesic effects

\section{How to apply this evidence in practice}

The application of evidence into practice should take into account multiple factors, not limited to: individual clinical expertise, patient's circumstances and owners' values, country, location or clinic where you work, the individual case in front of you, the availability of therapies and resources.

Knowledge Summaries are a resource to help reinforce or inform decision making. They do not override the responsibility or judgement of the practitioner to do what is best for the animal in their care. 


\section{Clinical Scenario}

The prevalence of osteoarthritis in geriatric dogs is high, and the affected population may have various comorbidities precluding the use of non-steroidal anti-inflammatory medication in relieving pain and discomfort associated with the condition. What evidence is there to support the use of tramadol as an alternative to non-steroidal anti-inflammatory medications?

\section{The evidence}

Two double-blinded controlled trials were evaluated. Overall, there is strong evidence that tramadol alone did not demonstrate any significant analgesic effects in dogs with osteoarthritis.

The randomised crossover controlled trial by Budsberg et al. (2018) provided strong evidence that the use of tramadol alone was insignificant in providing both objective and subjective improvements for dogs with osteoarthritis, with reference to both a negative and positive control. This study was well designed and conducted.

The non-randomised controlled trial by Malek et al. (2012) provided weak evidence that tramadol alone may provide subjective improvement based on client questionnaire. But there were no significant differences found in the objective outcomes measured between tramadol and the negative control. Interpretation and extrapolation of the results were also limited due to its poor study design.

\section{Summary of the evidence}

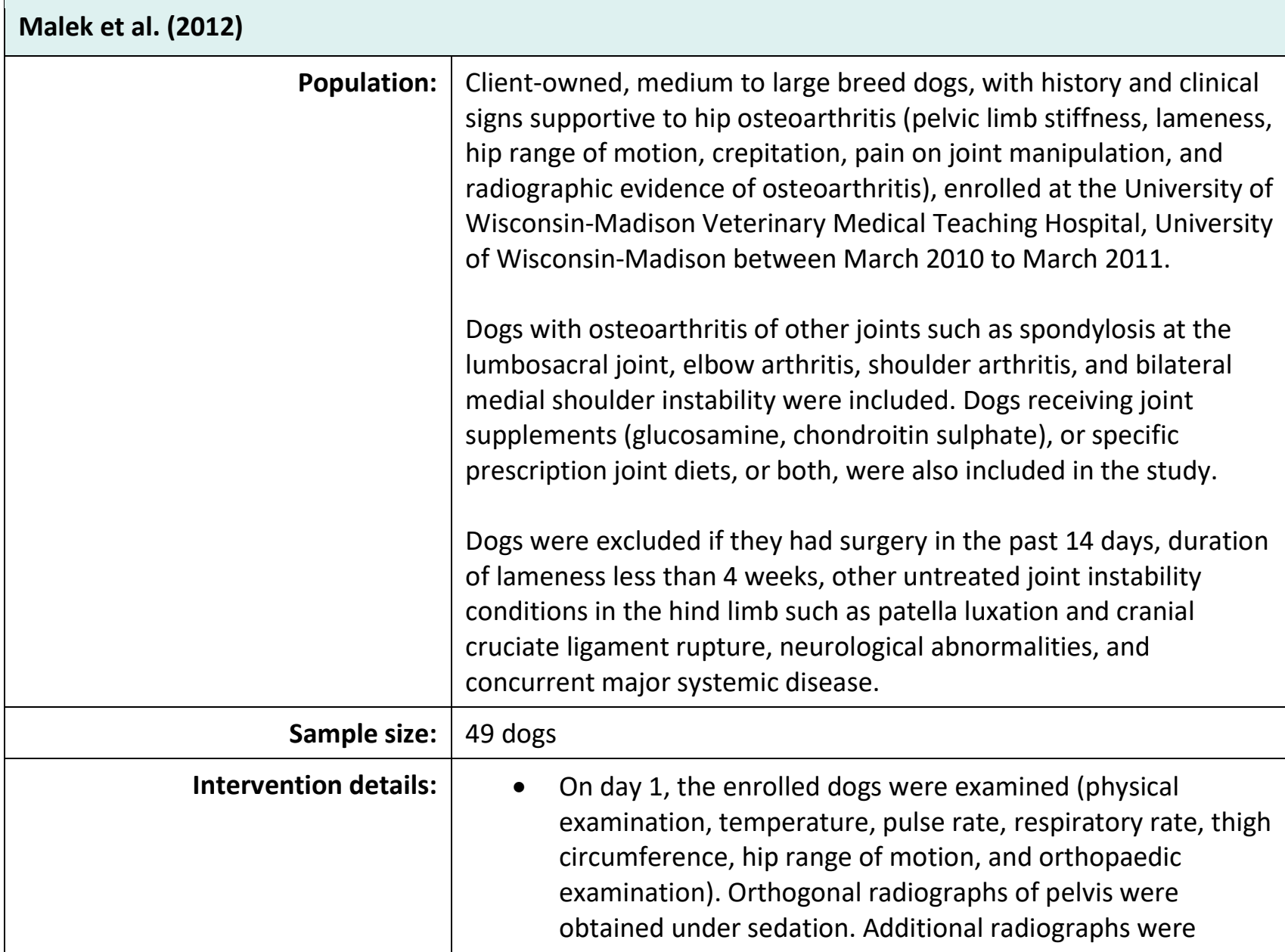




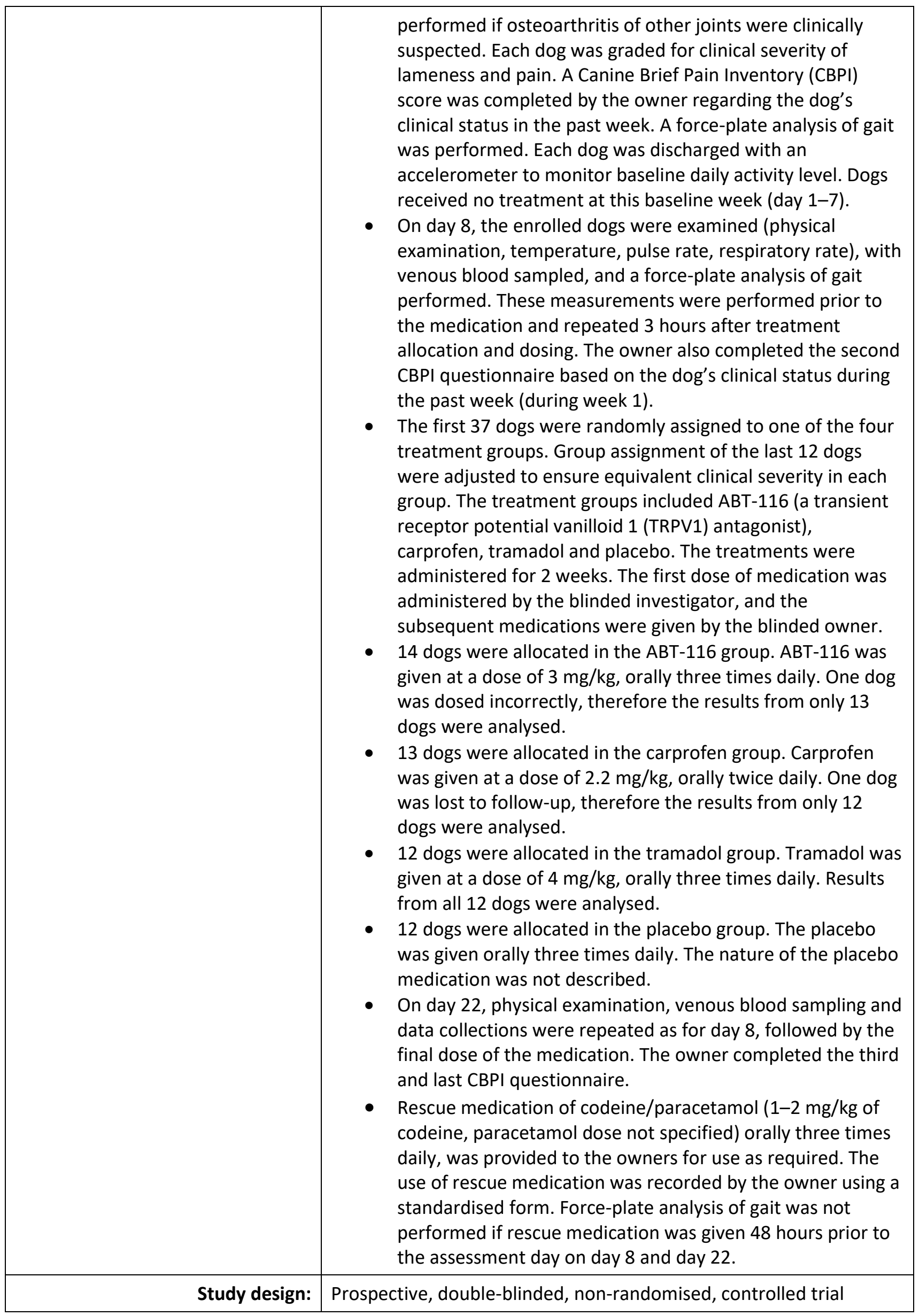




\begin{tabular}{|c|c|}
\hline Outcome studied: & $\begin{array}{l}\text { Objective measurements included measurement of plasma } \\
\text { drug concentration, rectal temperature, heart rate, respiratory } \\
\text { rate, hip range of motion and thigh circumference, } \\
\text { accelerometer measurement of dog activity, and force-plate } \\
\text { analysis of gait (changes in peak vertical force (PVF), vertical } \\
\text { impulse (VI) and falling slope (FS)), and the use of rescue } \\
\text { medication. } \\
\text { - Subjective measurement of the client scoring of the CBPI } \\
\text { questionnaire, which included the Pain Severity Score (PSS) and } \\
\text { Pain Interference Score (PIS). }\end{array}$ \\
\hline $\begin{array}{l}\text { Main findings: } \\
\text { (relevant to PICO question): }\end{array}$ & $\begin{array}{l}\text { Plasma concentration of tramadol were significantly decreased } \\
\text { in day } 22 \text { when compared to day } 8 \text {. } \\
\text { - No significant treatment effects on rectal temperature in the } \\
\text { tramadol group. } \\
\text { - No significant changes in total CBPI score, PSS or PIS between } \\
\text { treatment groups. } \\
\text { - Improvement in response to treatment were found in } \\
\text { carprofen and tramadol groups for total CBPI score, PSS and } \\
\text { PIS. } \\
\text { - No significant changes in total activity or daytime activity after } \\
\text { treatment in any treatment groups. } \\
\text { Night-time activity was higher after treatment in the tramadol } \\
\text { group. } \\
\text { Changes in PVF, VI and FS scores were not significantly different } \\
\text { between groups. } \\
\text { - PVF, VI and FS scores after treatment were not significantly } \\
\text { different from mean baseline, in all treatment groups. } \\
\text { There was a significant reduction in the number of days in the } \\
\text { use of rescue medication between the trial period for ABT-116 } \\
\text { (between week } 1 \text { and } 2 \text {, and week } 1 \text { and } 3 \text { ) and carprofen } \\
\text { groups (between week } 1 \text { and } 3 \text { ), but none for the tramadol } \\
\text { group. } \\
\text { No significant changes were found in the total activity or } \\
\text { daytime activity for any treatment groups. } \\
\text { The activity was higher during night-time period after } \\
\text { treatment for tramadol groups, but the change was statistically } \\
\text { insignificant. }\end{array}$ \\
\hline Limitations: & $\begin{array}{l}\text { - The study involved enrollment of dogs at a single academic site, } \\
\text { therefore sampled population may not be homogenous to the } \\
\text { general population of client-owned dogs with osteoarthritis. } \\
\text { - The study population included dogs with osteoarthritis of other } \\
\text { joints. Neuropathic pain associated with degenerative changes } \\
\text { in the lumbosacral joint is also possible. The inclusion of these } \\
\text { dogs may influence the effect of the treatment in question. } \\
\text { - The study population included dogs that were receiving joint } \\
\text { supplements, prescription joint diet, or both. The inclusion of } \\
\text { these dogs may act as confounding factors. } \\
\text { - The study was not a crossover study, therefore, may have } \\
\text { increased background variance. } \\
\text { - The method of randomisation was not specified. } \\
\text { - The study was not truly randomised, as the assignment of the } \\
\text { last } 12 \text { dogs was manipulated to ensure equivalent clinical } \\
\text { severity between groups. }\end{array}$ \\
\hline
\end{tabular}




\begin{tabular}{|l|l|}
\hline - The sedation for the radiographs on day 1 was not specified. \\
It is unknown if analgesics such as those with N-methyl-D- \\
aspartate (NMDA) receptor antagonistic effects were used, \\
as its use may attenuate or reverse chronic pain state. \\
Though only one dose was given, the consequential \\
confounding impact on the subjective and objective \\
assessment on pain is possible. \\
The study was not properly blinded, as carprofen was only \\
given twice daily, as opposed to the three times daily regime \\
for the other treatment groups. \\
The study had a small population size, and the results were \\
likely to be underpowered. \\
The author reported potential systematic error or plasma \\
sampling labelling error in some samples. \\
The author reported possible respondent bias as the owners \\
were not trained in recognising clinical signs related to \\
osteoarthritis. \\
Tramadol can be associated with sedative effects, which \\
may have confounding effects on the subjective assessment \\
of pain. The authors also commented that some owners may \\
have interpreted the sedative effects as pain. The validity of \\
the CBPI scoring may therefore be in question. \\
This study was funded by the manufacturer of ABT-116. \\
Two of the authors were employed by the manufacturer of \\
ABT-116, though the authors declared no competing \\
interests. \\
\hline
\end{tabular}

Budsberg et al. (2018)

\begin{tabular}{|c|c|}
\hline Population: & $\begin{array}{l}\text { Client-owned dogs of any age, sex, breed, weighing } 15-50 \mathrm{~kg} \text { with } \\
\text { clinical osteoarthritis and associated pain and dysfunction in at least } \\
\text { one elbow or stifle joint, enrolled at an academic site between } \\
\text { January } 2015 \text { to May } 2017 \text {. } \\
\text { Dogs were excluded if they had received corticosteroids or } \\
\text { polysulfated glycosaminoglycans parenterally or orally within } 30 \\
\text { days prior to the commencement of the study, with suspected or } \\
\text { confirmed systemic or local disease, evidence of joint instability, } \\
\text { joint surgery performed within the previous } 12 \text { months, and clinical } \\
\text { osteoarthritis in joints other than the elbow or stifle. }\end{array}$ \\
\hline Sample size: & 35 dogs \\
\hline Intervention details: & $\begin{array}{l}\text { - At baseline, dogs were physically examined, and screened } \\
\text { with complete blood count, biochemistry, urinalysis, } \\
\text { radiographs of all appendicular joints with signs of pain. } \\
\text { - All } 35 \text { dogs were assigned to each of the three treatment } \\
\text { regimens in a randomised order, using a computer } \\
\text { generated randomised drug dispensing schedule. } \\
\text { - Treatment sessions were separated by a minimum } 7 \text { day } \\
\text { washout period. } \\
\text { - The placebo treatment involved a placebo capsule (lactose } \\
\text { powder), given orally three times daily. }\end{array}$ \\
\hline
\end{tabular}




\begin{tabular}{|c|c|}
\hline & $\begin{array}{l}\text { - The carprofen treatment involved carprofen, at a dose of } 2.2 \\
\mathrm{mg} / \mathrm{kg} \text {, given orally twice daily with a placebo capsule (lactose } \\
\text { powder) in between. } \\
\text { - The tramadol treatment involved tramadol, at a dose of } 5 \\
\mathrm{mg} / \mathrm{kg} \text {, given orally three times daily, for } 10 \text { days. } \\
\text { - All drugs were tailored to each dog's body weight at the } \\
\text { beginning of the trial, encased in opaque identical appearing } \\
\text { capsules. Both the owners and the investigators were blinded } \\
\text { to the drug treatment. } \\
\text { Objective vertical ground reaction forces data and treatment } \\
\text { response assessments by CBPI scores were collected before } \\
\text { and at the end of each treatment period. } \\
\text { - Clients were supplemented with rescue medication of } \\
\text { codeine/paracetamol (1-2 mg/kg of codeine, paracetamol dose } \\
\text { not specified) three times daily as required. The provision of } \\
\text { rescue medication was recorded. }\end{array}$ \\
\hline Study design: & Prospective, double-blinded, randomised, controlled, crossover trial \\
\hline Outcome studied: & $\begin{array}{l}\text { Objective measurements include the vertical ground reaction } \\
\text { forces of VI and PVF value, and its percentage change from } \\
\text { baseline. } \\
\text { - Subjective measurement of CBPI score, and the proportion of } \\
\text { dogs deemed to have a positive response. A positive response } \\
\text { was defined as a score decrease between baseline and day } 10 \\
\text { of } \geq 1 \text { for PSS and } \geq 2 \text { for PIS. }\end{array}$ \\
\hline $\begin{array}{l}\text { Main findings: } \\
\text { (relevant to PICO question): }\end{array}$ & $\begin{array}{l}\text { - No significant difference in VI and PVF between baseline and } \\
\text { day } 10 \text { measurements for both placebo and tramadol } \\
\text { treatment. } \\
\text { - No significant difference in the percentage change from } \\
\text { baseline in VI and PVF between placebo and tramadol. } \\
\text { - Carprofen yielded significantly greater percentage change from } \\
\text { baseline in VI and PVF values than placebo or tramadol. } \\
\text { - No significant difference in CBPI score was identified between } \\
\text { tramadol and placebo. } \\
\text { - No significant difference in the proportion of dogs deemed to } \\
\text { have a positive response defined by the changes in scoring of } \\
\text { CBPI, between tramadol and placebo. } \\
\text { - Carprofen yielded significantly greater proportion of dogs with } \\
\text { positive response defined by the changes in scoring of CBPI, } \\
\text { compared to both tramadol and placebo. }\end{array}$ \\
\hline Limitations: & $\begin{array}{l}\text { - The study involved enrollment of dogs at a single academic site, } \\
\text { therefore sampled population may not be homogenous to the } \\
\text { general population of client-owned dogs with osteoarthritis. } \\
\text { - Sample size calculations were extrapolated from data of other } \\
\text { studies involving non-steroidal anti-inflammatory drugs, but } \\
\text { not tramadol. Type II error (falsely accepting the null } \\
\text { hypothesis that Tramadol has no significant difference to the } \\
\text { placebo in terms of the outcome studied) was possible with } \\
\text { inadequate sample size. } \\
\text { - Tramadol can be associated with sedative effects, which may } \\
\text { produce confounding effects on pain scoring. }\end{array}$ \\
\hline
\end{tabular}




\section{Appraisal, application and reflection}

Canine osteoarthritis is a highly prevalent condition, reported to be affecting as much as $80 \%$ of geriatric dogs (Johnston, 1997). While non-steroidal anti-inflammatory drugs are the typical medications of choice, alternatives such as tramadol, a synthetic opiate are often advocated. In one recent study, tramadol was reported to be used in as many as $19.64 \%$ (121/616) of dogs with the aim to relieve signs of pain and lameness associated with elbow joint disease (O'Neill et al., 2020). However, there are increasing concerns and recognitions of the lack of evidence from the literature regarding the use of tramadol (Davies, 2012). Furthermore, it had been demonstrated that canines produce minimal amounts of the active Odesmethyltramadol metabolite responsible for the proposed opioid agonistic effects of tramadol (Kögel, et al. 2014). The purpose of this Knowledge Summary is to determine the literature evidence available in supporting the clinical use of tramadol in dogs with osteoarthritis for pain relief.

Two prospective controlled trials were identified (Malek et al., 2012; and Budsberg et al., 2018). Both studies recognised the difficulty in evaluating pain, therefore multiple variables, including both objective and subjective outcome measures were utilised.

It should be commented that the sedative effect of tramadol may be a source of bias in the subjective assessment of pain. It is unknown if the sedative effects would affect these measurements positively or negatively. As Malek et al. (2012) anecdotally discussed the possibility that some owners may interpret the sedated patient to be in pain, although the opposite is also possible. Neither authors reported any incidence of excessively sedated dogs or other adverse events during the study.

It is also important to note that there is no consensus in the veterinary literature on the 'best' or preferred outcome measures in clinical research for canine osteoarthritis (Belshaw et al. 2016). Nevertheless, the similarities of the selected measure outcomes allowed these two studies to be closely compared.

Malek et al. (2012) and Budsberg et al. (2018) both used kinetic gait analyses as an objective measurement to assess the efficacy of tramadol. Such analysis had similarly been utilised in other studies evaluating the efficacy of other medications for animals with osteoarthritis (Budsberg et al., 1999; and Moreau et al., 2003). Consistently in both studies, tramadol did not yield any significant differences for both vertical impulse (VI) and peak vertical force (PVF) between baseline and after treatment. The changes in these measurements were also insignificant between tramadol and the negative control of placebo. In addition, Budsberg et al. (2018) also demonstrated that the positive control, carprofen, did in fact produce significant results comparing to both tramadol and placebo. This was in contrast with the results in Malek et al. (2012), the positive control, carprofen failed to produce any significant changes to placebo or tramadol. This was likely contributed by the small population enrolled in each group, hence the study was under powered. The validity of the results by Malek et al. (2012) was therefore in question.

Both studies utilised the Canine Brief Pain Inventory (CBPI) questionnaire as the subjective measurement of the efficacy of tramadol. The CBPI had been validated, with demonstrated responsiveness in detecting improvements in dogs with osteoarthritis after treatment (Brown et al., 2007; and Brown et al., 2008).

In the study by Malek et al. (2012), there were no significant differences of the percentage changes in the total score, pain severity score (PSS) and pain interference score (PIS) across all treatment groups. However, statistical significances were found between the score at the baseline and at the end of trial in the tramadol group, for all scores.

Budsberg et al. (2018) utilised the CBPI differently. Instead of evaluating the absolute changes between the scores, patients were distinguished as positive or negative responders based on the changes of the scores before and after the treatment period. A positive response was defined as a decrease in score of $\geq 1$ for PSS 
and $\geq 2$ for PIS. The proportion of positive responders were subsequently evaluated between groups for statistical differences. There were no significant differences between tramadol and placebo in the proportions of responders, and no significant differences of scores between the tramadol and placebo treatment in this study.

It had been proposed that the comparison between the mean or mean differences in scores between treatment groups, as Malek et al. (2012) did, only reflects a numerical change and may not give any indication of clinical improvements. The alternate approach in defining treatment success, as Budsberg et al. (2018) did, has the benefit in demonstrating the likelihood of treatment success in individual patients with decent statistical power (Brown et al., 2013). The direct comparison between the two studies on the subjective outcome measured was therefore difficult, due to the diverging methods of analysis. Nevertheless, the approach by Budsberg et al. (2018) may be favoured, since it is the clinical efficacy and success of the treatment that is of interest.

To further assess the strength of evidence between these two studies, the study designs were evaluated. While both studies were classified as prospective clinical trials, Budsberg et al. (2018) was superior in terms of study design, as it was a truly randomised, double-blinded, crossover study. Malek et al. (2012) was not truly randomised, as the assignment of the last 12 subjects was manipulated, though the rationale behind was to equate the clinical severity across the treatment groups. The blinding of the study was also likely to be compromised. The dosing frequencies were different between the treatment groups, as carprofen were given twice daily, and the rest of the treatment groups were given three times daily. Additionally, the study may be at risk of increased variance and bias as it was not a crossover study with low study population.

The above appraisal emphasised the strength of evidence provided by the study of Budsberg et al. (2018), whilst the validity of the results by Malek et al. (2012) were weak in comparison. Overall, there is strong evidence based on the reviewed literature, that tramadol alone did not demonstrate any significant analgesic effect in dogs with osteoarthritis.

\section{Methodology Section}

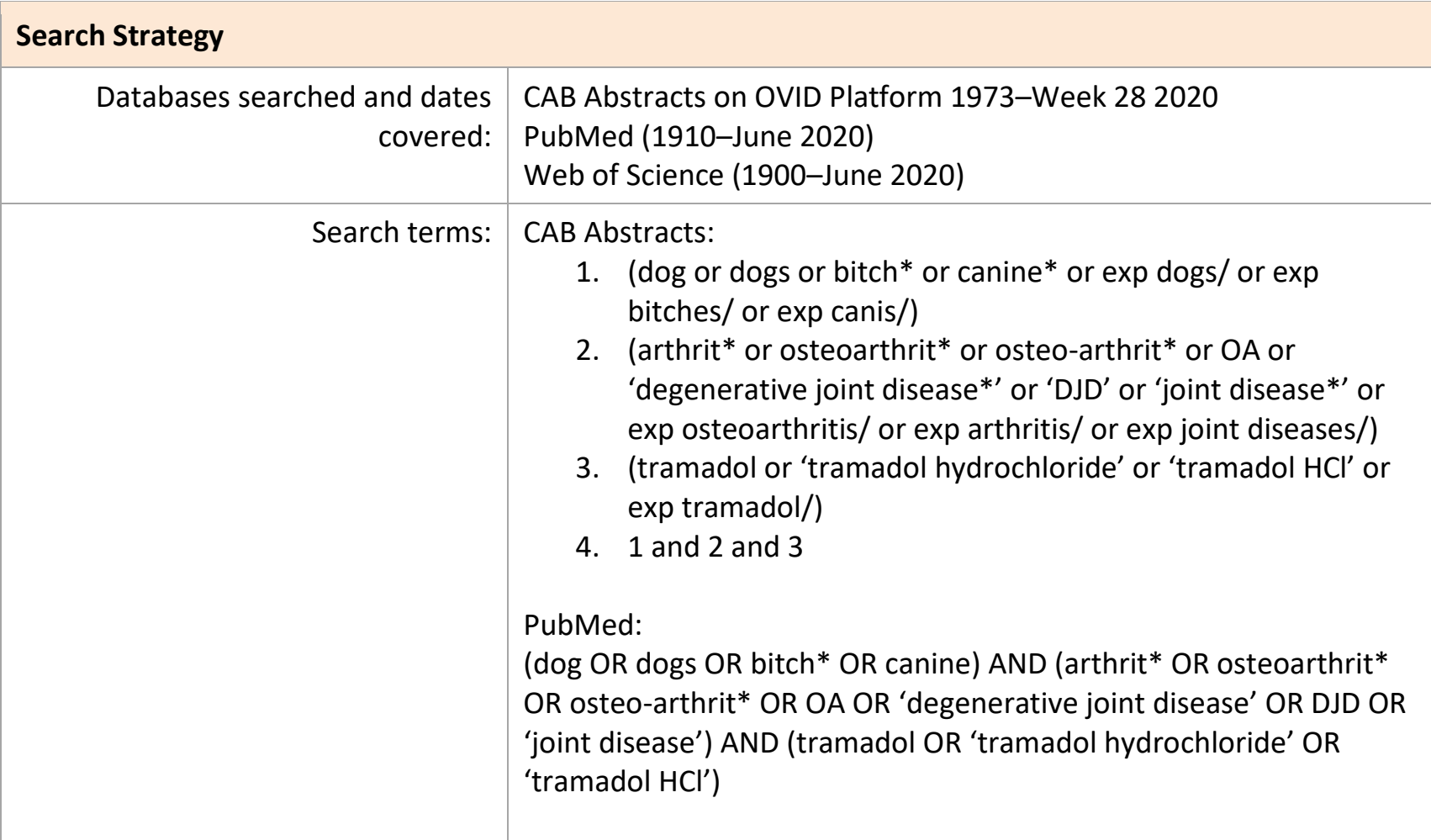




\begin{tabular}{|l|l|}
\hline & $\begin{array}{l}\text { Web of Science: } \\
\text { (dog OR dogs OR bitch* OR canine) AND (arthrit* OR osteoarthrit* } \\
\text { OR osteo-arthrit* OR OA OR 'degenerative joint disease' OR DJD OR } \\
\text { 'joint disease') AND (tramadol OR 'tramadol hydrochloride' OR } \\
\text { 'tramadol HCl') }\end{array}$ \\
\hline Dates searches performed: & O7 Jun 2020 \\
\hline
\end{tabular}

\section{Exclusion / Inclusion Criteria}

Numerous summaries, proceedings and non-systematic reviews are available in relation to the treatment of arthritis, due to its clinical prevalence. These are all excluded, as only original data are of interest to evaluate the literature support of the use of tramadol in dogs with osteoarthritis.

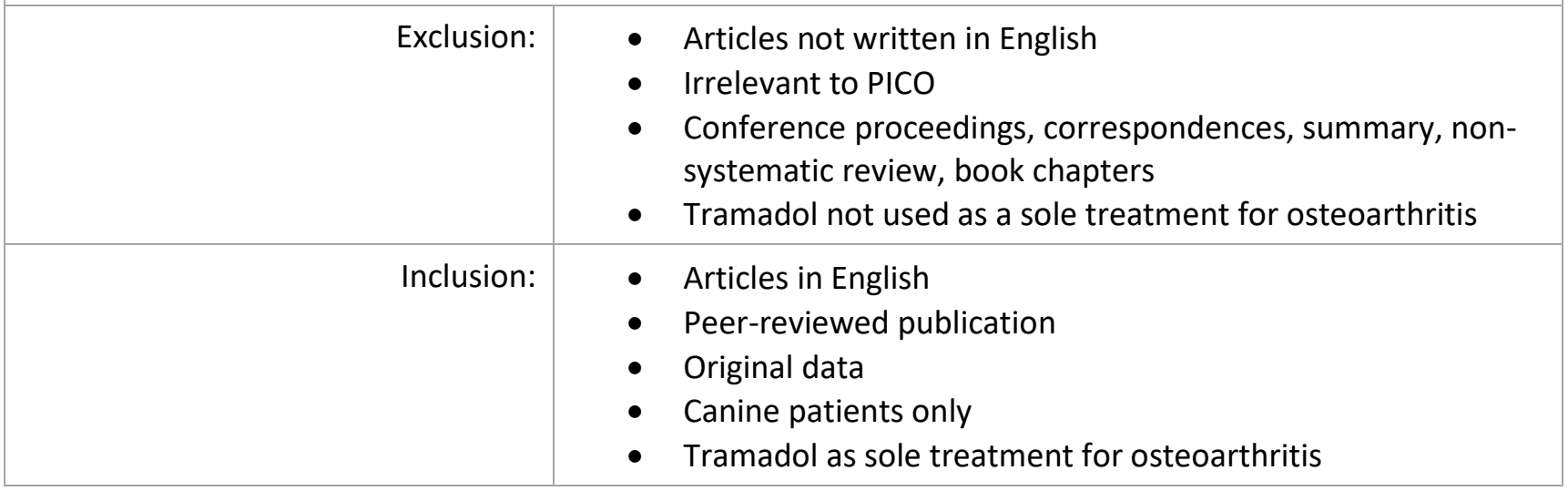

\begin{tabular}{|c|c|c|c|c|c|c|}
\hline \multicolumn{7}{|c|}{ Search Outcome } \\
\hline Database & $\begin{array}{c}\text { Number } \\
\text { of } \\
\text { results }\end{array}$ & $\begin{array}{l}\text { Excluded - } \\
\text { Not in } \\
\text { English }\end{array}$ & $\begin{array}{l}\text { Excluded - } \\
\text { Irrelevant to } \\
\text { PICO }\end{array}$ & $\begin{array}{l}\text { Excluded - } \\
\text { Conference } \\
\text { proceedings, } \\
\text { correspondence, } \\
\text { summary, non- } \\
\text { systematic } \\
\text { review, book } \\
\text { chapters }\end{array}$ & $\begin{array}{l}\text { Excluded - } \\
\text { Tramadol not } \\
\text { as sole } \\
\text { treatment }\end{array}$ & $\begin{array}{c}\text { Total } \\
\text { relevant } \\
\text { papers }\end{array}$ \\
\hline CAB Abs & 34 & 2 & 10 & 19 & 1 & 2 \\
\hline Medline & 15 & 0 & 6 & 6 & 1 & 2 \\
\hline $\begin{array}{l}\text { Web of } \\
\text { Science }\end{array}$ & 18 & 0 & 10 & 5 & 1 & 2 \\
\hline \multicolumn{6}{|c|}{ Total relevant papers when duplicates removed } & 2 \\
\hline
\end{tabular}




\section{CONFLICT OF INTEREST}

The authors declare no conflict of interest.

\section{REFERENCES}

1. Belshaw, Z., Asher, L. \& Dean, R.S. (2016). Systematic Review of Outcome Measures Reported in Clinical Canine Osteoarthritis Research. Veterinary Surgery. 45(4), 480-487. DOI: https://doi.org/10.1111/vsu.12479

2. Brown, D.C., Bell, M. \& Rhodes, L. (2013). Power of treatment success definitions when the Canine Brief Pain Inventory is used to evaluate carprofen treatment for the control of pain and inflammation in dogs with osteoarthritis. American Journal of Veterinary Research. 74(12), 1467-1473. DOI: https://doi.org/10.2460/ajvr.74.12.1467

3. Brown, D.C., Boston, R.C., Coyne, J.C. \& Farrar, J.T. (2007). Development and psychometric testing of an instrument designed to measure chronic pain in dogs with osteoarthritis. American Journal of Veterinary Research. 68(6), 631-637. DOI: https://doi.org/10.2460/ajvr.68.6.631

4. Brown, D.C., Boston, R.C., Coyne, J.C. \& Farrar, J.T. (2008). Ability of the canine brief pain inventory to detect response to treatment in dogs with osteoarthritis. Journal of the American Veterinary Medical Association. 233(8), 1278-1283. DOI: https://doi.org/10.2460/javma.233.8.1278

5. Budsberg, S.C., Johnston, S.A., Schwarz, P.D., DeCamp, C.E. \& Claxton, R. (1999). Efficacy of etodolac for the treatment of osteoarthritis of the hip joints in dogs. Journal of the American Veterinary Medical Association. 214, 206-210.

6. Budsberg, S.C., Torres, B.T., Kleine, S.A., Sandberg, G.S. \& Berjeski, A.K. (2018). Lack of effectiveness of tramadol hydrochloride for the treatment of pain and joint dysfunction in dogs with chronic osteoarthritis. Journal of the American Veterinary Medical Association. 252(4), 427-432.

DOI: https://doi.org/10.2460/javma.252.4.427

7. Davies, M. (2012). Control of off-label use of medicines. Veterinary Record. 170(26), 680. DOI: https://doi.org/10.1136/vr.e4399

8. Johnston, S.A. (1997). Osteoarthritis: Joint Anatomy, Physiology, and Pathobiology. Veterinary Clinics of North America: Small Animal Practice. 27(4), 699-723. DOI: https://doi.org/10.1016/s01955616(97)50076-3

9. Kögel, B., Terlinden, R. \& Schneider, J. (2014). Characterisation of tramadol, morphine and tapentadol in an acute pain model in Beagle dogs. Veterinary Anaesthesia \& Analgesia. 41(3), 297-304. DOI: https://doi.org/10.1111/vaa.12140

10. Malek, S., Sample, S.J., Schwartz, Z., Nemke, B., Jacobson, P.B., Cozzi, E.M., Schaefer, S.L., Bleedorn, J.A., Holzman, G. \& Muir, P.. (2012). Effect of analgesic therapy on clinical outcome measures in a randomized controlled trial using client-owned dogs with hip osteoarthritis. BMC Veterinary Research. 8, 185. DOI: https://doi.org/10.1186/1746-6148-8-185

11. Moreau, M., Dupuis, J., Bonneau, N.H. \& Desnoyers, M. (2003). Clinical evaluation of a nutraceutical, carprofen and meloxicam for the treatment of dogs with osteoarthritis. Veterinary Record. 152(11), 323-329. DOI: https://doi.org/10.1136/vr.152.11.323

12. O'Neill, D.G., Brodbelt, D.C., Hodge, R., Church, D.B. \& Meeson, R.L. (2020). Epidemiology and clinical management of elbow joint disease in dogs under primary veterinary care in the UK. Canine Medicine and Genetics. 7, 1. DOI: https://doi.org/10.1186/s40575-020-0080-5 


\section{EVIIDEFeE

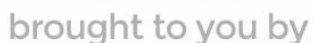 \\ RCVS KNOWLEDGE}

\section{Intellectual Property Rights}

Authors of Knowledge Summaries submitted to RCVS Knowledge for publication will retain copyright in their work, and will be required to grant RCVS Knowledge a non-exclusive license of the rights of copyright in the materials including but not limited to the right to publish, re-

publish, transmit, sell, distribute and otherwise use the materials in all languages and all media throughout the world, and to license or permit others to do so.

\section{Disclaimer}

Knowledge Summaries are a peer-reviewed article type which aims to answer a clinical question based on the best available current evidence. It does not override the responsibility

of the practitioner. Informed decisions should be made by considering such factors as individual clinical expertise and judgement along with patient's circumstances and owners' values. Knowledge Summaries are a resource to help inform and any opinions expressed within the Knowledge Summaries are the author's own and do not necessarily reflect the view of the RCVS Knowledge. Authors are responsible for the accuracy of the content. While the

Editor and Publisher believe that all content herein are in accord with current recommendations and practice at the time of publication, they accept no legal responsibility

for any errors or omissions, and make no warranty, express or implied, with respect to material contained within.

For further information please refer to our Terms of Use.

RCVS Knowledge is the independent charity associated with the Royal College of Veterinary Surgeons (RCVS). Our ambition is to become a global intermediary for evidence based veterinary knowledge by providing access to information

that is of immediate value to practicing veterinary professionals and directly contributes to evidence based clinical decision-making.

\section{https://www.veterinaryevidence.org/}

RCVS Knowledge is a registered Charity No. 230886.

Registered as a Company limited by guarantee in England and Wales No. 598443.

Registered Office: Belgravia House, 62-64 Horseferry Road, London SW1P 2AF

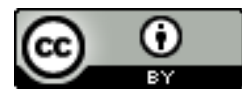

This work is licensed under a Creative Commons Attribution 4.0 International License. 